\title{
Research on Methodology in Acquisition of College Data Structure Course
}

\author{
Lishuang Zhao \\ College of information science and Technology, Bohai University, Jinzhou, P.R. China \\ jz_zls@163.com
}

Keywords: Data structure; methodology; practice; evaluation

\begin{abstract}
Theoretically based on Multiple Intelligence, Constructivism and Humanism, the thesis explores and analyzes principles of methodology in acquisition such as content, teachers and learners, interactions among them, curriculum activities, settings and modern educational technology involved. The thesis also probes the basic processes and operating procedures of the methodology which has specific qualifications and procedures to be implemented and applied. The thesis exemplifies the course of Data Structure and expounds on the specific application schemes of its methodology, including creating objective-centered contexts, conducting the learners to construct knowledge through multidimensional activities, as well as directing them to participate in practice and accomplish the feedback of their study.
\end{abstract}

\section{Introduction}

Data Structure is an import and basic course of computer and related subjects. The "Data Structures and Algorithms" course ranks the first among 9 main subjects in "computer science teaching program in 1993 " [1]. The technical thinking contained in data structure has a strong orientation in software design for students. The effect of course impacts directly on students' way of thinking in the field of software design and on the improvement of students' study.

Teaching model is a strategy theory about how to organize, design and control the teaching activities [2]. It is a specialized teaching theory and its aim is to achieve certain teaching goals. Several typical teaching models have been formed in "Data Structure" Course. They are: teaching cases of model data structures; focusing on source program and data structure teaching model; data structure teaching model based on visualization. There are some limitations. According to the teaching practice in the data structure, the author analyses the constituent elements of the teaching model by referring to the advantages of the existed teaching models and construct a new teaching model which can adapt to the development of new situation and capacity-fostering for students.

\section{Construction of the Teaching Model in Data Structure Program}

The so-called composition elements refer to the teaching conditions when utilizing the teaching model or the variable quantity tokens which affect the application of the teaching model. Practice has showed that there are many elements which can affect the application of the teaching models; teaching methods; such as teaching environment and modern education technology as shown in the following figure. Teaching materials; teachers; students; teaching activities; teaching organization and modern education technology construct a pentagonal pyramid [3]. Each element is a vertex. Different comprehension or angle can be got from different vertex. Cross relationship has been built up among all the elements.

1. Teaching Materials

Teaching materials consist of three basic elements-information, symbols and medium-which impart knowledge and skills to students. Multiple-leveled teaching materials includes: main teaching materials + reference teaching materials + experimental teaching materials + assistant teaching resources. The multiple-leveled teaching materials and the network resources provide the platform for teacher's preparing the lecture; teacher's delivering a lecture, students' study and the 
mutual communication between the teacher and the students, so the maximal teaching profits have been realized.

\section{Teachers and Students}

The teacher in the teaching model discussed in the thesis possesses diverse roles. Teachers are guiders for students' seeking after new knowledge and cooperative learning. Teachers should give students encouragement and put forward new goals when students succeed. Teachers are inspectors and monitors of teaching and learning. Teachers can monitor and evaluate themselves and adjust their teaching by the students' leaning situation and feedback and their own feeling of teaching in the teaching practice. Students are the subject in the teaching activities who embody the teaching effect directly and at the same time affect the teaching results. Students are complete and independent individuals who have both universality and individuality characterized by an unbalanced feature. The modern technology which has been applied into the teaching helps to stimulate students' interest in learning. It corresponds to the age features and is helpful to develop students' subjectivity and to foster students' thinking ability and individuality.

\section{Teaching organization forms}

Chinese traditional teaching organization forms are individual teaching and group teaching. This form respects students fully and makes optimization of individual development, but this form wastes more many teaching resources and requires higher level of the teacher resources. So it's impossible to accomplish individual teaching and group teaching in the current period in the view of existing situation. But we can construct multi-leveled teaching organization in the course of data structure program. We adopt the big whole class teaching model in which there exists individual and group teaching forms. The idea behind it is "big class-group-individual-group-big class" [4]. It gives consideration to both big class and individual and group.

\section{Teaching activities}

Being a multi-dimensional system, teaching activities are the central element of the teaching mode, as is shown in Fig. 1. Depending on different teaching content and students' interests and internal demand, students actively participate in the teaching process, thus attaining the goal of their inquiry and innovation [5]. Multiple permutations and combinations can be chosen based on the teaching content in the teaching process. Therefore, multi-dimensional combination teaching process has great flexibility.

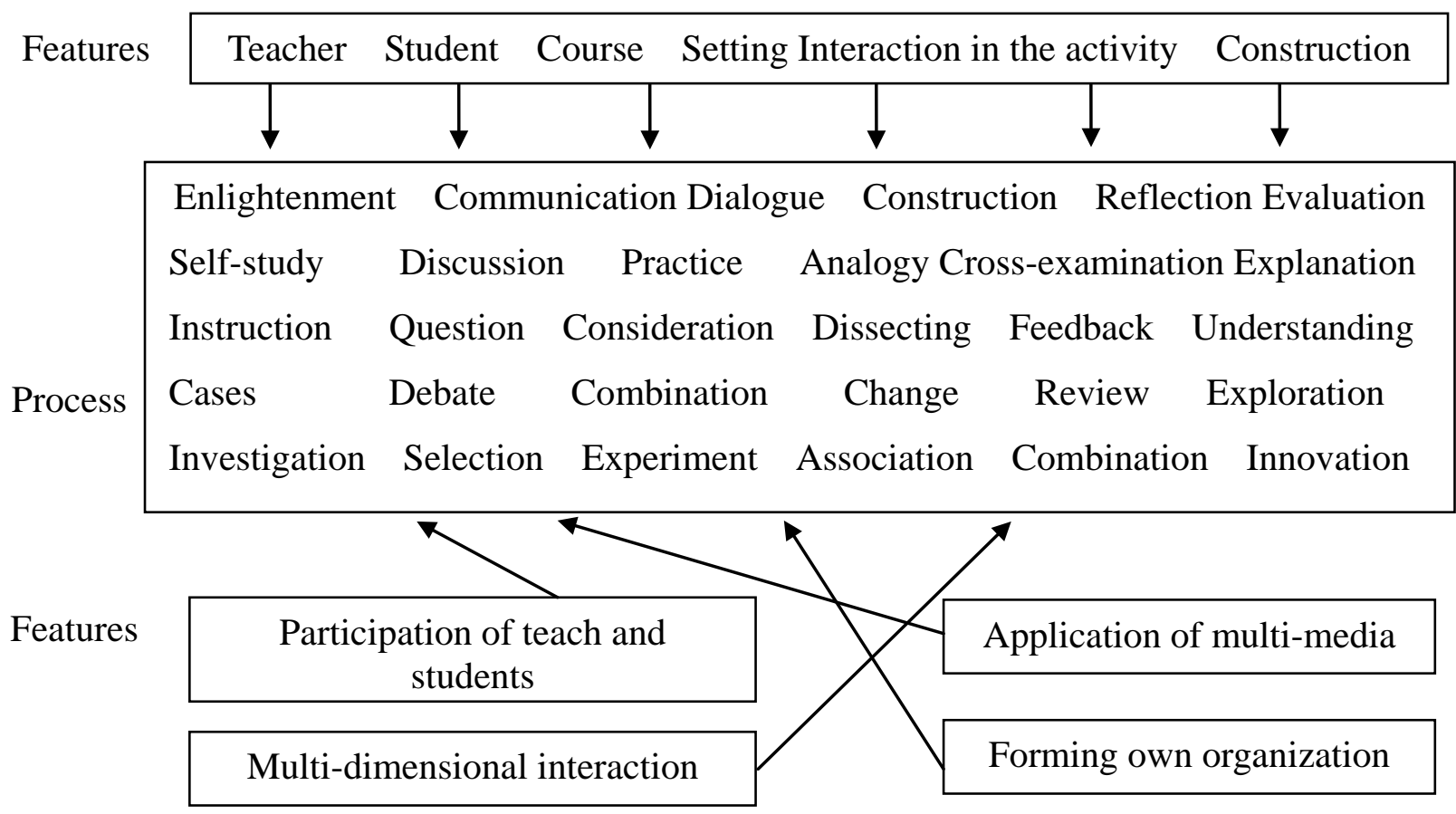

Fig. 1. Multi-dimensional combination teaching diagram 
Modern education technology is one of the important elements in teaching mode. In China, one significant aspect in the modern education technology research area is the research of combination of modern education technology and subjects teaching, the research of construction of new educational and teaching mode by using modern education technology, and the research of promotion of all-round development education" [6]. In the paper, the teaching mode to be constructed is to apply the research of the new idea and new technology in modern education technology to concrete education and teaching.

The above five elements are indispensable in the teaching mode of Data Structure Course. Each of them plays an irreplaceable role in the mode.

\section{Operational Program of Data Structure Course Teaching Model}

The Teaching model has its procedures to be implemented and applied. As shown in Fig. 2.

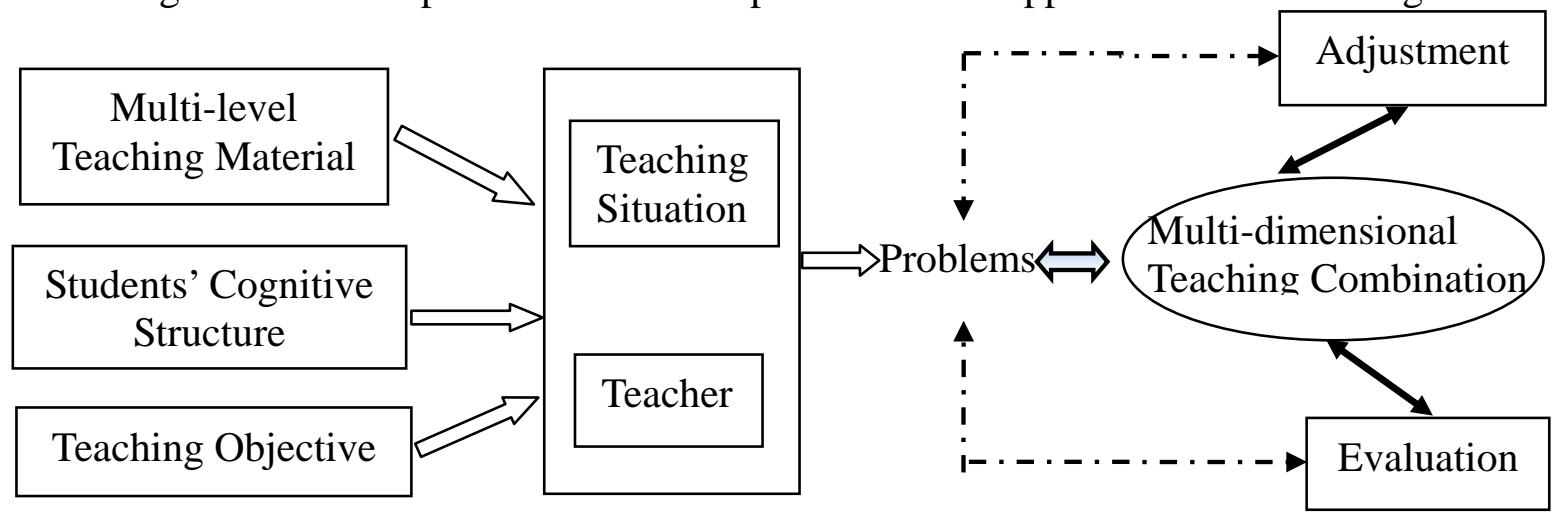

Fig. 2. Teaching mode operational procedure diagram

1. Determination of teaching situation based on materials and students' cognitive structure

Multi-level teaching material is a broad definition, including various information resources. It is concretized knowledge and technology [7]. Cognitive structure is the structure formed in the learners' mind and is transformed from life experiences, textbooks and knowledge structure of classroom teaching. Before classroom teaching, teachers have to study and know about students' cognitive structure. Teaching objectives are the learning effect expected by the students after their participation in the teaching activities. The presentation of classroom teaching objective enables students to maintain the learning object and bring their initiative into full play.

On the basis of multi-level teaching materials, students' cognitive structure and teaching objectives, teachers create a teaching situation in favor of inspiring students' attention and interest. Learning is adaptation. Creating teaching situations is favorable for students' horizontal and longitudinal knowledge transfer, thus enabling students to adapt to learning. Consequently, teaching situations are based on the principle of "proximal development zone" and are close to students' original cognitive structure. Teaching objectives are determined accordingly, presented in the situation and run through the whole classroom teaching.

2. Combination of teaching activities according to multi-dimensional system

Multi-dimensional combination system means choosing multiple permutation and combination modes to teach according to teaching contents of different kinds and nature. In the teaching process, teachers employ multiple teaching approaches synthetically and characterize problems multiply, thereby causing students to deepen their understanding and application of the acquired knowledge. Constructive learning is accomplished by joint efforts of the students themselves, teachers and other tutors. Teachers should design worth-meditative and meaningful questions based on teaching content of teaching activities, in which students should consider the questions first and then try to solve the problems. Resorting to modern teaching means, such as organizing in-class teaching activities based on multi-dimensional teaching, providing learning resources and recommending related websites, teachers can direct students to probe learning, automatically construct, practically operate and solve problems.

3. Evaluation and adjustment 
Evaluation is favorable for the students' horizontal and longitudinal knowledge transfer, and for their corrections of misunderstanding [8]. The evaluation as an element of composing the operating process of data structure teaching mode refers to the thinking strategies taken in the activity process centered around the problems, including teacher's evaluation of problems and students, students' evaluation of problems and themselves, and students-students evaluation. Adjustment is monitoring strategy of the cognitive process, including feedback of the process. Monitoring is conducted in the same process of feedback and evaluation. Evaluation and adjustment are conducted simultaneously while students participate in the learning activities. Only by evaluating can students find their inadequacy and adjust their learning intentionally. The process of adjustment is also that of constant evaluation.

\section{Conclusion}

Data Structure course is listed in the university key construction courses. Multi-media courseware of Data Structure, calculus programs of typical algorithm, part of animation demonstration software of Data Structure operation have been finished step by step. Syllabus of Data Structure course design and experiment reports standards and assessment criteria have been worked out. In the process of experimental teaching of students majoring in information and management system and computer science and technology, we have achieved desirable teaching effect and received good feedback from the students. Despite the author's limited ability and limitations in the teaching process, we still hold the fact that with the perfection of Data Structure teaching mode itself, its running in with teaching practice, and the ever deepening of teaching reform and practice, the teaching mode under discussion will be increasingly mature and its operability, scientificalness and rationality will be increasingly stronger.

\section{Acknowledgements}

The research work was supported by Social Science Foundation of China under Grant No. L14BTJ002.

\section{References}

[1] Yang Xiaobo, "Design and Realization of Visualized CAI System of Data Structure," Computer Appliance and Software, vol. 25, no. 9, pp.196-198, 2008.

[2] Wang Dexing, Hu Xuegang, Zhang Yuhong, Zhang Jing, "Discussion of Reform and Innovation of Data Structure Course, " Hefei University of Technology Journal, vol. 22, no. 5, pp.94-98, 2008.

[3] Zhang Fengxiang, "Symposium of National Computer New Science \& Technology and Computer Education, " Chengdu: Southwest Transportation University Press, 2008.

[4] Yao Qiaohong, "Exploration into Constructing Class Interactive Teaching Mode by Modern Education Technology, " Master’s degree of Northwestern Normal University, 2001.

[5] Yu Shengquan, Wu Juan, "Combination of Information and Courses: Teaching Mode and Means in Cyber times, " Shanghai: Shanghai Education Press, 2005.

[6] Zhang Zili, "Correlation Research into Learning Interest and Academic Score under the flexible teaching mode, " Master’s degree of Tianjing Normal University, 2007.

[7] Chen Yuwen, "Importance of Valuing Source Program in Data Structure, " Higher Education Forum, no.1, pp.73-75, 2004.

[8] Chen Guolong, Wang Xiaodong, Fu Qingxiang, "Teaching Reform and Practice of Algorithm and Data Structure Course, "Higher Institutions Science Education, no.3, pp.61-64, 2003. 